\title{
Atypical Wenckebach periodicity simulating Mobitz II AV block
}

\author{
NABIL EL-SHERIF, JUAN ARANDA, BENJAMIN BEFELER, AND \\ RALPH LAZZARA
}

From the Section of Cardiology, Veterans Administration Hospital and the University of Miami School of Medicine, Miami, Florida, USA

SUMMARY Eleven patients were studied and a total of 144 Wenckebach cycles in the AV node and 118 Wenckebach cycles in the His-Purkinje system were analysed to determine the incidence of typical and atypical Wenckebach periodicity, with particular emphasis on one variant of atypical Wenckebach that may simulate a Mobitz type II block. This pseudo-Mobitz II pattern was defined as a long Wenckebach cycle in which, at least, the last three beats of the cycle show relatively constant PR intervals (variation of no more than $0.02 \mathrm{~s}$ in surface leads and no more than $10 \mathrm{~ms}$ in His bundle electrograms) and in which the PR interval immediately following the blocked beat is shorter than the PR interval before the block by $0.04 \mathrm{~s}$ or more. Atypical Wenckebach cycles were found to be more common than the typical variety at both the AV node $(67 \%)$ and His-Purkinje system (69\%). The pseudo-Mobitz II pattern was seen in 19 per cent of atypical AV nodal Wenckebach periods and in 17 per cent of atypical His-Purkinje system Wenckebach cycles. The need to discern a 'classical' Mobitz II block from a pseudo-Mobitz II pattern, especially in the setting of an acute inferior myocardial infarction, is emphasised.

Two types of second degree atrioventricular block (AV block) were originally described by Wenckebach $(1899,1906)$ and Hay (1906) from analysis of the AC interval of the jugular pulse. After the introduction of the electrocardiogram these were classified by Mobitz (1924) as types I and II. Type I AV block, also known as Mobitz type I or the Wenckebach phenomenon, is defined as intermittent failure of AV conduction preceded by progressive lengthening of AV conduction times. Type II AV block, also known as Mobitz type II block, is characterised by intermittent failure of AV conduction which occurs unheralded and in which the PR intervals remain constant before the dropped beat. The clinical significance of the two types of second degree AV block was first recognised by Mobitz (1924) who suggested that type II block might be the first step to Adams-Stokes attacks and complete permanent dissociation. This was further emphasised in recent years with the introduction of intensive care and electrocardiographic monitoring for acute myocardial infarction (Langendorf and Pick, 1968; Rosen et al., 1970; Touboul et al., 1972). In a previous study on the pathophysiology of second degree AV block (El-Sherif et al., 1975) we emphasised one variant of atypical Wenckebach

Received for publication 1 November 1977 periodicity which is frequently mislabelled as Mobitz type II block. This variant which will be referred to in this study as pseudo-Mobitz II block represents records of long Wenckebach cycles in which the last several conducted beats before the blocked impulse showed no perceptible or a few milliseconds increment of conduction delay. In two recent systematic analyses of Wenckebach cycles in the AV node (Denes et al., 1975; Friedman et al., 1975) several variants of atypical Wenckebach periodicity were described and the atypical arrangement was found to be more common than the typical one. However, the pseudo-Mobitz II arrangement was not described.

In the present study we describe several patients with second degree AV block localised either in the AV node or His-Purkinje system, in which some of their records displayed the pseudo-Mobitz II arrangement. The ability to discern a 'classical' Mobitz II pattern from a pseudo-Mobitz II arrangement can have both electrophysiological and clinical significance.

\section{Subjects and methods}

Eleven patients with second degree AV block were studied some of whose tracings displayed the 
pseudo-Mobitz II arrangement. A pseudo-Mobitz II arrangement in a standard electrocardiographic lead was defined as follows: a long Wenckebach cycle in which, at least, the last three beats of the cycle show relatively 'constant' PR intervals (variation of no more than $0.02 \mathrm{~s}$ ) and in which the PR interval immediately following the blocked beat is shorter than the PR interval before the blocked impulse by $0.04 \mathrm{~s}$, or more. In all patients a His bundle electrogram was recorded using previously described techniques (Scherlag et al., 1969). In patients with second degree AV block secondary to acute myocardial infarction His bundle recordings were obtained during either the insertion or removal of a temporary ventricular pacemaker. In the His bundle electrogram, the $\mathrm{AH}$ interval was measured from the first rapid deflection of the $A$ wave to the first rapid deflection of the His bundle potential and was taken to represent AV nodal conduction time (normal 50-120 ms) (Narula, 1973). The HV interval was measured from the His bundle deflection to the earliest ventricular activation recorded on either the intracardiac electrogram or surface leads and reflected His-Purkinje conduction time (normal 34 to $45 \mathrm{~ms}$ ) (Narula, 1973). All available spontaneous periods of second degree AV block were analysed for the presence of typical and atypical
Wenckebach periodicity, the latter including the pseudo-Mobitz II arrangement. Records showing significant sinus arrhythmia (variation of the PP or AA intervals of more than $60 \mathrm{~ms}$ during a single Wenckebach period) were excluded. Typical Wenckebach periodicity (Wenckebach and Winterberg, 1927) was considered to be present when the record showed: (1) the first PR interval of a cycle (AH interval in AV nodal block and HV interval in HisPurkinje block) was the shortest; (2) progressive lengthening of the PR interval with the increment between the first and second conducted beats being the largest; (3) progressive decrease in the RR (VV) intervals; (4) a pause produced by the non-conducted $\mathrm{P}$ wave equal to the difference between the last PR (before the pause) and the first PR (after the pause) subtracted from twice the PP interval. Atypical Wenckebach period failed to meet one or more criteria for typical Wenckebach periodicity. A pseudo-Mobitz II arrangement in the His bundle electrogram was defined as follows. A long Wenckebach cycle in which the last three beats of the cycle showed relatively constant PR interval (variation in the $\mathrm{AH}$ or $\mathrm{HV}$ intervals of no more than $10 \mathrm{~ms}$ ) and in which the first PR interval following the blocked beat was shorter than the last PR interval of the preceding cycle by 40 or more ms.

Table 1 Clinical and electrocardiographic data

\begin{tabular}{|c|c|c|c|c|c|c|}
\hline Case no. & Age & ECG findings & Clinical diagnosis & Digoxin & Management & Follow-up electrocardiogram \\
\hline 1 & 55 & $\begin{array}{l}\text { Old anteroseptal MI, } \\
\text { recent inferior MI, } \\
\text { BD-LBBB }\end{array}$ & CHD & - & Temporary pacemaker & $\begin{array}{l}1: 1 \text { AV conduction } \\
3 \text { days later }\end{array}$ \\
\hline 2 & 63 & $\begin{array}{l}\text { Old anteroseptal MI, } \\
\text { recent inferior MI, } \\
\text { BD-LBBB }\end{array}$ & CHD & - & Temporary pacemaker & $\begin{array}{l}1: 1 \text { AV conduction } \\
48 \text { hours later }\end{array}$ \\
\hline 3 & 61 & $\begin{array}{l}\text { Old anteroseptal } \mathrm{MI} \text {, } \\
\text { recent inferior } \mathrm{MI} \text {, } \\
\text { BD-LBBB }\end{array}$ & CHD & - & Temporary pacemaker & $\begin{array}{l}1: 1 \text { AV conduction } \\
5 \text { days later }\end{array}$ \\
\hline 4 & 67 & $\begin{array}{l}\text { Spontaneous Wenckebach } \\
\text { and } 2: 1 \mathrm{AV} \text { block }\end{array}$ & HHD & - & Permanent pacemaker & $\begin{array}{l}2: 1 \text { AV conduction } \\
6 \text { m later }\end{array}$ \\
\hline 5 & 62 & $\begin{array}{l}\text { Spontaneous Wenckebach } \\
\text { and } 2: 1 \mathrm{AV} \text { block, VPCs }\end{array}$ & $\begin{array}{l}\text { No apparent } \\
\text { heart disease }\end{array}$ & - & Permanent pacemaker & $\begin{array}{l}2: 1 \text { AV conduction } \\
9 \text { m later }\end{array}$ \\
\hline 6 & 69 & $\begin{array}{l}\text { Wenckebach, } 2: 1 \mathrm{AV} \\
\text { block, VPCs, PACs }\end{array}$ & $\begin{array}{l}\text { HHD } \\
\text { COPD, diabetes }\end{array}$ & + & Quinidine & $\begin{array}{l}1^{\circ} \mathrm{AV} \text { block } \\
6 \mathrm{~m} \text { later }\end{array}$ \\
\hline 7 & 72 & $\begin{array}{l}\text { Old anteroseptal MI, } \\
\text { recent latero-posterior } \\
\text { MI, old RBBB + LAH }\end{array}$ & CHD & + & $\begin{array}{l}\text { Temporary followed } \\
\text { by permanent } \\
\text { pacemaker }\end{array}$ & $\begin{array}{l}\text { RBBB, LAH, and } \\
2: 1 \mathrm{AV} \text { conduction } \\
6 \mathrm{~m} \text { later }\end{array}$ \\
\hline 8 & 68 & $\begin{array}{l}\text { Recent anteroseptal MI, } \\
\text { acute RBBB + LAH }\end{array}$ & CHD & - & $\begin{array}{l}\text { Temporary followed } \\
\text { by permanent } \\
\text { pacemaker }\end{array}$ & $\begin{array}{l}1: 1 \text { AV conduction } \\
6 \text { m later }\end{array}$ \\
\hline 9 & 67 & $\begin{array}{l}\text { Recent anterior } \mathrm{MI} \text {, } \\
\text { acute RBBB }\end{array}$ & CHD & - & $\begin{array}{l}\text { Temporary followed } \\
\text { by permanent } \\
\text { pacemaker }\end{array}$ & $\begin{array}{l}1: 1 \mathrm{AV} \text { conduction } \\
10 \mathrm{~m} \text { later }\end{array}$ \\
\hline 10 & 69 & $\begin{array}{l}\text { Old RBBB + LAH, } \\
\text { ST-T changes, junctional } \\
\text { ectopic beats }\end{array}$ & ASHD & + & Permanent pacemaker & $\begin{array}{l}\text { RBBB + LAH, } \\
2: 1 \text { AV conduction } \\
8 \text { m later }\end{array}$ \\
\hline 11 & 58 & $\begin{array}{l}\text { Old RBBB + LAH, } \\
\text { VPCs, ST-T changes }\end{array}$ & HHD & + & Permanent pacemaker & $\begin{array}{l}\text { Complete heart block with } \\
\text { idioventricular pacemaker }\end{array}$ \\
\hline
\end{tabular}

MI, myocardial infarction; CHD, coronary heart disease; HHD, hypertensive heart disease; COPD, chronic obstructive pulmonary disease; BD, bradycardia-dependent; LBBB, left bundle-branch block; RBBB, right bundle-branch block; LAH, left anterior hemiblock; PACs, premature atrial contractions; VPCs, ventricular premature contractions; ASHD, arteriosclerotic heart disease. 
Table 2 Electrophysiological data

\begin{tabular}{|c|c|c|c|c|c|}
\hline Case no. & $\begin{array}{l}\text { Site of second } \\
\text { degree } A V \text { block }\end{array}$ & $A H$ interval ${ }^{\star}$ (ms) & $H V$ interval ${ }^{\star}(m s)$ & $\begin{array}{l}\text { Largest increment of } \\
\text { conduction delay (ms) }\end{array}$ & $P R$ interval ${ }^{\star}(s)$ \\
\hline 1 & AVN & 220 & 50 & 100 & 0.32 \\
\hline 2 & AVN & 200 & 45 & 90 & 0.30 \\
\hline 3 & AVN & 210 & 45 & 100 & 0.30 \\
\hline 4 & AVN & 280 & 50 & 80 & 0.38 \\
\hline 5 & AVN & 190 & 40 & 60 & 0.26 \\
\hline 6 & AVN & 270 & 45 & 80 & 0.36 \\
\hline 7 & HPS & 90 & 60 & 210 & 0.22 \\
\hline 8 & HPS & 95 & 65 & 50 & 0.20 \\
\hline 9 & HPS & 100 & 70 & 60 & 0.22 \\
\hline 10 & HPS & 115 & 70 & 100 & 0.22 \\
\hline 11 & HPS & 105 & 65 & 120 & 0.26 \\
\hline
\end{tabular}

* Measured in the opening beat of a Wenckebach cycle.

AVN, AV node; HPS, His-Purkinje system.

\section{Results}

Clinical and electrocardiographic data of the 11 patients studied are shown in Table 1 and the electrophysiological studies are summarised in Table 2. The site of Wenckebach second degree AV block was localised in the AV node in 6 patients and in the His-Purkinje system distal to the site of His bundle recording in 5. In 3 patients, AV nodal Wenckebach conduction was secondary to an acute diaphragmatic infarction. All 3 patients had evidence of an old anteroseptal infarction in the electrocardiogram and they all showed a transient bradycardia-dependent left bundle-branch block. In these patients $1: 1 \mathrm{AV}$ conduction was restored 3 to 5 days from the onset of symptoms of acute myocardial infarction. In 3 patients His-Purkinje Wenckebach conduction was seen in the setting of an acute myocardial infarction (anteroseptal in 2 and latero-posterior in 1). All patients with AV nodal Wenckebach conduction had normal intraventricular conduction (apart from the transient bradycardia-dependent bundle-branch block). On the other hand, all 5 patients with His-Purkinje
Wenckebach cycles had right bundle-branch block and in 4 of the 5 a left anterior hemiblock was also present. Paroxysmal AV block was not documented in any of the 11 patients during their initial hospital stay.

A total of 144 Wenckebach cycles in the AV node and 118 Wenckebach cycles in the His-Purkinje system was analysed. These were all spontaneous Wenckebach cycles and included both electrocardiographic tracings and His bundle electrograms. Only 4:3 or longer Wenckebach periods were analysed. Table $3 \mathrm{~A}$ shows the number of typical and atypical Wenckebach periods localised in the AV node and His-Purkinje system and Table 3B illustrates the frequency of the different variants of atypical Wenckebach periods including the pseudoMobitz II arrangement. Atypical Wenckebach periods were more common than typical ones and their incidence was approximately the same at both the AV node $(67 \%)$ and the His-Purkinje system $(69 \%)$. Periods greater than 5:4 were all atypical. There were 4 variants of atypical Wenckebach period, the most frequent of which were periods where the last increment increased from the pre-

Table 3 Typical and atypical Wenckebach periodicity

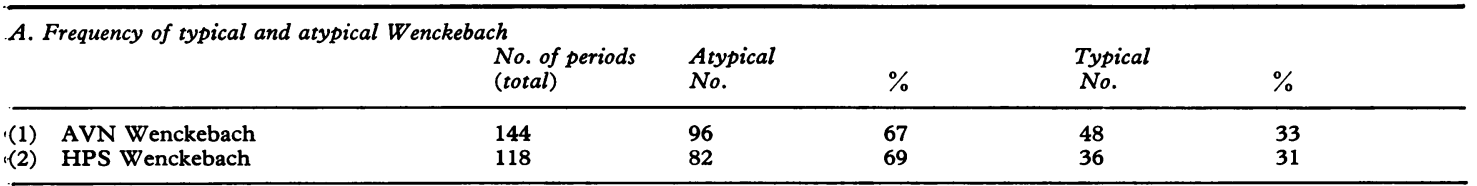

B. Frequency of variants of atypical Wenckebach Type of variants .

AVN Wenchebach

\begin{tabular}{lll} 
& No. of periods $\%$ & No. of periods \\
\hline
\end{tabular}

(1) Last increment increases

(2) Last increment largest

(3) Constant or decreasing PR intervals at least once

(4) Constant PR intervals of last 3 or more beats

$\begin{array}{llll}42 & 44 & 38 & 46 \\ 16 & 17 & 14 & 17 \\ 20 & 21 & 16 & 20 \\ 18 & 19 & 14 & 17\end{array}$


vious increment. This applied for both $\mathrm{AV}$ nodal and His-Purkinje atypical Wenckebach periods. The pseudo-Mobitz II arrangement represented 19 per cent of atypical AV nodal Wenckebach periods and 17 per cent of atypical His-Purkinje Wenckebach cycles. One noticeable difference between Wenckebach cycles including the pseudo-Mobitz II pattern localised at the AV node and the His-Purkinje system was the duration of the PR interval of the beat immediately following the blocked impulse (i.e. the opening beat of the cycle). In the 6 patients with AV nodal Wenckebach conduction it ranged from $0.26-$ $0.38 \mathrm{~s}$ (average $0.32 \mathrm{~s}$ ) while in 5 patients with HisPurkinje Wenckebach conduction it was shorter $(0.20$ to $0.26 \mathrm{~s}$, with an average of $0.22 \mathrm{~s})$. The difference was statistically significant $(P<0.01)$. The relatively long $P R$ interval of the opening beat of AV nodal Wenckebach cycles was the result of $\mathrm{AV}$ nodal conduction time ( $\mathrm{AH}$ interval) remaining significantly prolonged in the beat following the long pause.
Illustrative recordings of pseudo-Mobitz II AV block in the AV node and His-Purkinje system are shown in Figs. 1-4.

\section{Discussion}

Since the time of Wenckebach, atypical Wenckebach periodicity was frequently noted (Campbell, 1943; Dressler and Swiller, 1958; Castillo et al., 1971). In two recent systematic analyses of Wenckebach cycles in the AV node, atypical Wenckebach periodicity was found to be more common than the typical one (Denes et al., 1975; Friedman et al., 1975). Our findings on AV nodal Wenckebach cycles are in agreement with those studies. Furthermore, the present study shows that atypical Wenckebach periodicity in the His-Purkinje system is also more common than the typical one. Though several variants of atypical Wenckebach cycle were described in the above two studies, the pseudoMobitz II arrangement was not mentioned. The

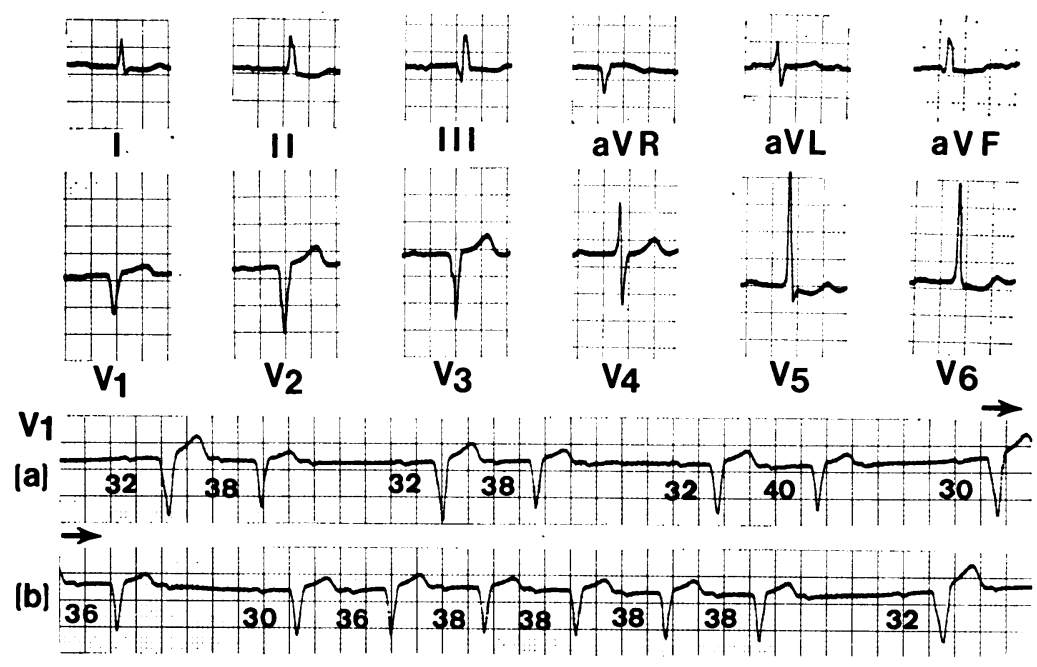

Fig. 1 Case 1, pseudo-Mobitz II block in the AV node. Recordings were obtained from a 55-year-old man two days after the onset of an acute inferior wall myocardial infarction. The 12-lead electrocardiogram shows an old anteroseptal infarction and intraventricular conduction defect of the incomplete left bundle-branch block pattern. Newly developed $Q$ waves in leads II, III, and aVF are compatible with an acute inferior wall infarction. The continuous rhythm strip at the bottom shows 4 successive 3:2 Wenckebach cycles followed by a long 7:6 cycle. PR intervals are listed in hundredths of a second. During the long Wenckebach cycle the main increment of $A V$ conduction delay occurred between the first and second beats of the cycles. The PR intervals remained almost constant (variation of $0.02 \mathrm{~s}$ or less) for 5 successive beats before the blocked $P$ wave. This was followed by significant shortening of the PR interval in the beat that immediately followed the blocked impulse. This represents a pseudo-Mobitz II arrangement. Also note the presence of varying degrees of bradycardia-dependent left bundle-branch block pattern in the opening beats of the Wenckebach cycles that followed the longer pauses. 


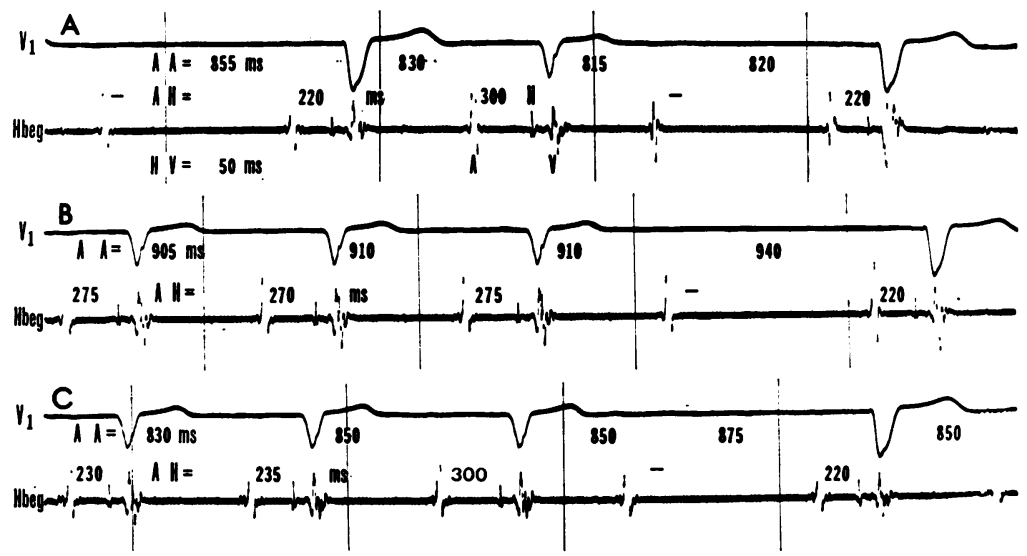

Fig. 2 Case 1, His bundle electrogram obtained during the insertion of a temporary ventricular pacemaker. Panel $A$ shows a 3:2 AV nodal Wenckebach cycle. Note that the PR interval of the opening beat of the Wenckebach cycle that followed the long pause remained much prolonged. This was accounted for by a long $A H$ interval. Panel B illustrates the last 3 beats of a long 6:5 Wenckebach cycle and shows almost constant $P R$ and $A H$ intervals before the blocked $P$ wave. After the blocked impulse the AH interval shortened. This represents a pseudo-Mobitz II pattern. Panel $C$ illustrates another variant of atypical Wenckebach periodicity in which the last increment is the largest. Panels $A$ to $C$ also show the bradycardia-dependent left bundle-branch block. The change in intraventricular conduction was not accompanied by a change in the $H V$ interval. $A, V$, and $H$, atrial, ventricular, and His bundle deflections, respectively; Hbeg, His bundle electrogram. Time lines are set at 1 sintervals.

failure to recognise this variant of atypical Wenckebach has resulted in several experimental and clinical reports suggesting that the AV node may occasionally show a Mobitz II second degree AV block (Rosen et al., 1971; Spear and Moore, 1971; Yeh et al., 1972). Critical analysis of some of these records shows that they actually represented a pseudo-Mobitz II arrangement in which the last conducted beats of a Wenckebach cycle before the blocked impulse showed no perceptible or a few ms increment of conduction delay, while the first conducted beat subsequent to block showed significant shortening of AV nodal conduction time. The misconception probably stemmed from the fact that the diagnosis of Mobitz II block was originally based on the presence of constant PR intervals before the dropped beat without emphasis on the necessity for a constant PR interval in the beats immediately preceding and immediately following the block (Barold and Friedberg, 1974; El-Sherif et al., 1975). However, as was recently pointed out (Barold and Friedberg, 1974; El-Sherif et al., 1975), in a 'classical' Mobitz II block, a short PR interval of the first beat after the block may not represent a genuine AV conduction but rather a fortuitous AV junctional escape beat. Analysis of sufficiently long rhythm strips usually helps to unravel these cases. Similar to what was found in this study, some of the previously published records showing pseudoMobitz II arrangement in the AV node displayed distinct prolongation of AV nodal conduction time before as well as after the blocked impulse.

Although the present study illustrated the equally common occurrence of atypical Wenckebach periodicity at both the AV node and His-Purkinje system and also emphasised the pseudo-Mobitz II arrangement at both sites, it shed no light on the mechanism(s) of the atypical Wenckebach cycle. In fact, the mechanisms for the typical Wenckebach phenomenon in the AV node are not fully elucidated. Interplay of several factors was suggested including decremental conduction and both electrotonic prolongation and shortening of action potentials (Schaffer and Depasquale, 1973). In a typical Wenckebach periodicity, the second impulse of the cycle suffers the largest increment of delay. This was explained on the basis that this impulse encounters decremental conduction and prolongation of the refractory period resulting from electrotonus and temporal shift (Schaffer and Depasquale, 1973). The mechanisms for atypical Wenckebach periodicity in the AV node are even more speculative. Spon- 


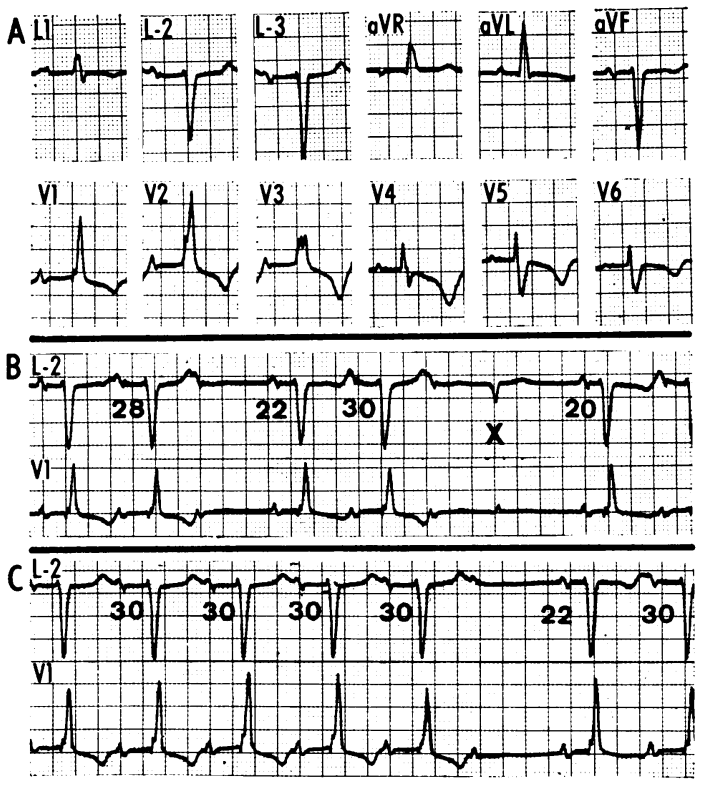

Fig. 3 Case 10, pseudo-Mobitz II block in the His-Purkinje system. Recordings were obtained from a 69-year-old man with arteriosclerotic heart disease who was ondigoxin for the last three years for congestive heart failure. Four months before admission, the patient noticed frequent episodes of dizzy spells. The 12-lead electrocardiogram showed right bundle-branch block, left axis deviation, and inversion of $T$ waves in praecordial leads (panel $A$ ). $A$ silent myocardial infarction was ruled out by normal levels of serum enzymes and the absence of serial changes in the QRS and ST-T complexes. The rhythm strip in panel $B$ shows 3:2 Wenckebach cycles. $P R$ intervals are also listed in hundredths of a second. Panel $C$ illustrates a pseudo-Mobitz II pattern. Note the presence of almost constant PR intervals in the last 4 beats of a long Wenckebach cycle and significant shortening of the PR interval after the blocked impulse. $X$, premature junctional $P$ wave.

taneous changes in the sympathetic and parasympathetic tone (Katz and Pick, 1956) or slight sinus arrhythmia in the presence of pronounced depression of AV nodal conduction have been invoked (Spear and Moore, 1971). Inhomogeneous or asynchronous and dissociated spread of the advancing wave front sometimes resulting in concealed AV nodal re-entry has also been postulated to explain the sudden prolongation of $\mathrm{AV}$ nodal conduction time of the last beat before block (Denes et al., 1975). As regards atypical Wenckebach cycles in the HisPurkinje system, spontaneous variations in the vagal tone are unlikely to be responsible in view of the equivocal role of vagal impulses on conduction in the His-Purkinje system. A mechanism invoking inhomogeneous and dissociated spread of the activation wave front is a more plausible explanation for atypical Wenckebach cycles at both the AV node and His-Purkinje system. This mechanism finds support from in vitro observations in the AV node (Watanabe and Dreifus, 1965) and depressed HisPurkinje system (Cranefield et al., 1971; El-Sherif et al., 1975).

The ability to discern a pseudo-Mobitz II arrangement from a 'classical' Mobitz II block is particularly relevant in the setting of an acute myocardial infarction. Though a pseudo-Mobitz II arrangement can occur at both the AV node and His-Purkinje system, there are usually sufficient differences in the standard electrocardiogram to allow accurate localisation of the site of lesion. Besides the regular association of AV nodal pseudoMobitz II block with an acute inferior rather than an anterior myocardial infarction, normal intraventricular conduction is usually present. However, a transient bradycardia-dependent left bundle-branch block can occur as was recently emphasised (Lie $e t$ al., 1974). On the other hand, a pseudo-Mobitz II block in the His-Purkinje system is seen in the setting of an acute anterior infarction and is consistently associated with right bundle-branch block and often left anterior hemiblock. A significant electrocardiographic difference between a pseudo-Mobitz II arrangement in the AV node and His-Purkinje system is the length of the PR interval in the opening beat of the Wenckebach cycle. In AV nodal block it usually remains very prolonged $(0.26$ to $0.38 \mathrm{~s}$, with an average of $0.32 \mathrm{~s}$ ). On the other hand, it is usually less than $0.26 \mathrm{~s}$ in pseudo-Mobitz II block in the His-Purkinje system.

In all cases in which a pseudo-Mobitz II arrangement was observed in the electrocardiogram, analysis of other records disclosed typical Wenckebach periodicity and/or other variants of atypical Wenckebach cycle. Thus, in the setting of an acute myocardial infarction especially of the inferior wall, the pseudo-Mobitz II pattern should not create undue concern of a high risk of paroxysmal AV block that is usually associated with the 'classical' Mobitz II block (El-Sherif et al., 1975). In the present study patients with acute inferior wall infarction and a pseudo-Mobitz II block showed no evidence of paroxysmal block and $1: 1 \mathrm{AV}$ conduction returned within 3 to 5 days from the onset of infarction. Thus, the indication for a temporary pacemaker in this group of patients should not be any different from other patients with acute inferior wall infarction who develop second degree AV block of the Wenckebach type (Tans and Lie, 1976). Furthermore, a permanent pacemaker is usually not 


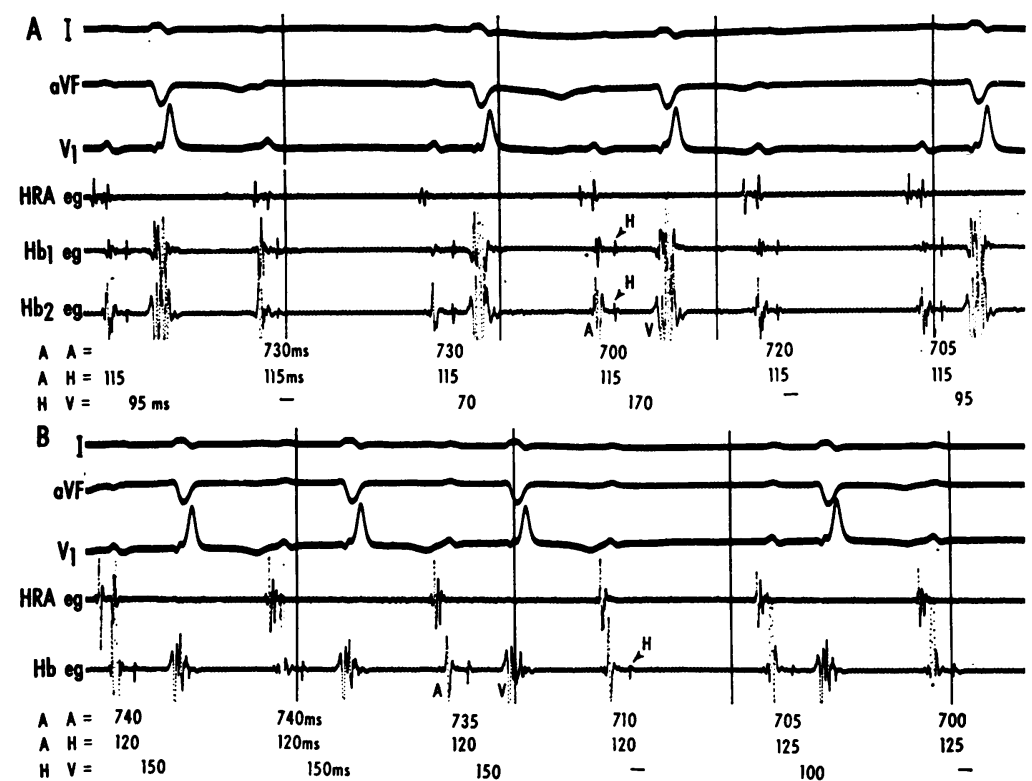

Fig. 4 Case 10, His bundle electrograms that correspond to the two ryhthm strips in Fig. 3, panels $B$ and $C$. Panel $A$ shows a 3:2 Wenckebach conduction in the His-Purkinje system distal to the site of His bundle recording. Panel $B$ illustrates the last three beats of a long 7:6 Wenckebach cycle. Note the presence of much prolonged but constant $H V$ intervals before block distal to the His bundle deflection. The HV interval shortened in the beat immediately after the blocked impulse.

This represents a pseudo-Mobitz II pattern. $A, V$, and $H$, atrial, ventricular, and His bundle deflections; $H R A$ eg, high right atrial electrogram; $\mathrm{Hb}_{1}$ eg and $\mathrm{Hb}_{2}$ eg, two His bundle electrograms. Time lines are set at $1 \mathrm{~s}$ intervals.

indicated since the conduction abnormality is frequently transient.

In a recent review of the pathophysiology of second degree and paroxysmal AV block the conventional classification of second degree $A V$ block into Mobitz II and Wenckebach types was criticised (El-Sherif et al., 1975). However, we suggested that the use of the conventional classification by clinicians should not be discouraged until a more complete formulation of the pathophysiology and clinical history of AV conduction disorders is available, when more evidence has been accumulated. In the meantime, both clinicians and electrophysiologists should be aware of some of the inherent limitations in using the terms Mobitz II and Wenckebach type blocks.

\section{References}

Barold, S. S., and Friedberg, H. D. (1974). Second degree atrioventricular block. A matter of definition. American fournal of Cardiology, 33, 311-315.

Campbell, M. (1943). Partial heart block with dropped beats. British Heart fournal, 5, 55-66.

Castillo, C., Maytin, O., and Castellanos, A., Jr. (1971). His bundle recordings in atypical $\mathrm{A}-\mathrm{V}$ nodal Wenckebach block during cardiac pacing. American fournal of Cardiology, 27, 570-576.

Cranefield, P. F., Klein, H. O., and Hoffman, B. F. (1971). Conduction of the cardiac impulse. 1. Delay, block and oneway block in depressed Purkinje fibers. Circulation $R e-$ search, 28, 199-219.

Denes, P., Levy, L., Pick, A., and Rosen, K. M. (1975). The incidence of typical and atypical A-V Wenckebach periodicity. American Heart Fournal, 89, 26-31.

Dressler, W., and Swiller, S. L. (1958). Atypical Wenckebach periods with dropped atrial beats. American fournal of Cardiology, 2, 575-581.

El-Sherif, N., Scherlag, B. J., and Lazzara, R. (1975). Pathophysiology of second degree atrioventricular block: a unified hypothesis. American fournal of Cardiology, 35, 421-434.

Friedman, H. S., Gomes, J. A. C., and Haft, J. L. (1975). An analysis of Wenckebach periodicity. Fournal of Electrocardiology, 8, 307-315.

Hay, J. (1906). Bradycardia and cardiac arrhythmia produced by depression of certain of the functions of the heart. Lancet, 1, 139-143.

Katz, L. N., and Pick, A. (1956). Clinical Electrocardiography. Part I. The Arrhythmias. Lea and Febiger, Philadelphia; Kimpton, London.

Langendorf, R., and Pick, A. (1968). (Editorial) Atrioventricular block type II (Mobitz)-its nature and clinical significance. Circulation, 38, 819-821.

Lie, K. I., Wellens, H. J., Schuilenburg, R. M., and Durrer, 
D. (1974). Mechanism and significance of widened QRS complexes during complete $\mathrm{A}-\mathrm{V}$ block in acute inferior myocardial infarction. American fournal of Cardiology, 33, 833-839.

Mobitz, W. (1924). Uber die unfallständige Störung der Erregungsüberleitung zwischen Vorhof und Kammer des menschlichen Herzens. Zeitschrift für die gesamte experimentelle Medizin, 41, 180-237.

Narula, O. S. (1973). Conduction disorders in the A-V transmission system. In Cardiac Arrhythmias, pp. 259-291. Ed. by L. S. Dreifus and W. Likoff. Grune and Stratton, New York.

Rosen, K. M., Loeb, H. S., Gunnar, R. M., and Rahimtoola, S. H. (1971). Mobitz type II block without bundle-branch block. Circulation, 44, 1111-1119.

Rosen, K. M., Loeb, H. S., Chuquimia, R., Sinno, M. Z., Rahimtoola, S. H., and Gunnar, R. M. (1970). Site of heart block in acute myocardial infarction. Circulation, 42, 925-933.

Schaffer, A. I., and Depasquale, N. P. (1973). Mechanism of Wenckebach A-V block and the obligatory ventricular echo. Cardiovascular Research, 7, 696-702.

Scherlag, B. J. Lau, S. H., Helfant, R. H., Berkowitz, W. D., Stein, E., and Damato, A. N. (1969). Catheter technique for recording His bundle activity in man. Circulation, 39, 13-18.

Spear, J. J., and Moore, E. N. (1971). Electrophysiologic studies on Mobitz type II second-degree heart block. Circulation, 44, 1087-1095.
Tans, A. C., and Lie, K. I. (1976). A-V nodal block in acute myocardial infarction. In The Conduction System of the Heart, p. 655 . Ed. by H. J. J. J. Wellens, K. I. Lie, and M. J. Janse. Stenfert Kroese, Leiden.

Touboul, P., Clement, C., Porte, J., Magrina, J., and Delahaye, P. (1972). Étude électrophysiologique des troubles de conduction auriculoventriculaire dans l'infarctus myocardique récent. Archives des Maladies du Coeur et des Vaisseaux, 65, 1287-1298.

Watanabe, Y., and Dreifus, L. S. (1965). Inhomogenous conduction in the A-V node: a model for re-entry. American Heart fournal, 70, 505-514.

Wenckebach, K. F. (1899). Zur Analyse des unregelmässigen Pulses. Zeitschrift für klinische Medizin, 37, 475-488.

Wenckebach, K. F. (1906). Beiträge zur Kenntnis der menschlichen Herztätigkeit. Archiv für Anatomie und Physiologie (Physiologische Abteilung), 297-354.

Wenckebach, K. F., and Winterberg, H. (1927). Unregelmassige Herztatigkeit, pp. 305, 309, and 310. Wilhelm Engelman, Leipzig.

Yeh, B. K., Tao, P., and deGuzman, N. (1972). Mobitz type II A-V block as a manifestation of digitalis toxicity. fournal of Electrocardiology, 5, 74-77.

Requests for reprints to Dr Nabil El-Sherif, Veterans Administration Hospital, 800 Poly Place, Brooklyn, New York 11209, USA. 